\title{
Quercetin and sulforaphane in combination suppress the progression of melanoma through the down-regulation of matrix metalloproteinase-9
}

\author{
SAURABH J. PRADHAN, ROSALIN MISHRA, PRIYANKA SHARMA and GOPAL C. KUNDU
}

National Center for Cell Science, Pune 411 007, India

Received June 26, 2010; Accepted August 16, 2010

DOI: $10.3892 /$ etm.2010.144

\begin{abstract}
Malignant melanoma is one of the most common types of cancer in the US and worldwide. The epidemiological data suggest that dietary modification may reduce the incidence of this disease. Quercetin (3,5,7,3',4'-tetrahydroxyflavone), a flavonoid isolated from onion, exhibits anti-oxidant, anti-inflammatory and anti-cancer effects. D,L-sulforaphane [1-isothiocyanato-4-(methylsulfinyl)butane], a cruciferous vegetable-derived isomer isolated from broccoli, is highly effective in protection against cancer. Matrix metalloproteinases (MMPs), extracellular matrix degrading enzymes, are involved in embryogenesis, inflammation, angiogenesis and cancer. MMP-9 in particular plays a crucial role in the regulation of invasion, tumor growth and metastasis. Previous studies have reported that both quercetin and sulforaphane independently reduce tumor growth and metastasis in breast, prostate, lung and other types of cancers. However, the combined effects of quercetin and sulforaphane on the regulation of tumor growth and the mechanism(s) of actions underlying this process have not yet been investigated. In the present study, we report for the first time that quercetin and sulforaphane in combination inhibit the proliferation and migration of melanoma (B16F10) cells more effectively than either compound used alone. Moreover, these compounds in combination significantly suppressed melanoma growth as compared to their individual use in a mouse model. This combined effect was predominantly due to a decrease in MMP-9 expression in the mouse tumors. Taken together, our
\end{abstract}

Correspondence to: Dr Gopal C. Kundu, National Center for Cell Science, Pune 411 007, India

E-mail:kundu@nccs.res.in

Abbreviations: QUE, quercetin; SFN, sulforaphane; MMP-9, matrix metalloproteinase-9; DAPI, 4'6-diamidino-2 phenylindole; SDS-PAGE, sodium dodecyl sulfate-polyacrylamide gel electrophoresis

Key words: quercetin, sulforaphane, matrix metalloproteinase-9, melanoma growth findings revealed that the administration of quercetin and sulforaphane in combination rather than alone may be a more effective approach for the treatment of malignant melanoma.

\section{Introduction}

Malignant melanoma is one of the most common types of cancer in the US as well as worldwide. It is an aggressive disease with high metastatic potential and resistance to many cytotoxic agents (1). Melanoma cells have low levels of spontaneous apoptosis, and chemotherapeutic drugs function by inducing apoptosis (1). Many dietary agents, including kinase inhibitors, have been inversely correlated to the spread of malignant melanoma (2-4). The alkylating agent dacarbazine is currently being used in clinical trials in combination with novel therapeutic agents (4). Quercetin (3,5,7,3',4'-tetrahydroxyflavone) is a flavonoid isolated from onion, whereas sulforaphane [1-isothiocyanato-4-(methylsulfinyl)-butane] is a member of an isothiocyanate family of chemopreventive agents isolated from broccoli. The anti-cancer properties of these compounds have been demonstrated in a number of malignancies, including prostate, breast, skin and liver cancers (5-9). Previous reports suggest that quercetin is an anti-oxidant and anti-inflammatory compound (10,11). Others have indicated that sulforaphane acts as a potential HDAC inhibitor and an inducer of various pro-apoptotic molecules (12-14). Sulforaphane was also found to inhibit prostate tumor growth and lung metastasis in a melanoma model $(15,16)$.

Matrix metalloproteinases (MMPs) are extracellular matrix proteins known to play a crucial role in normal physiological processes, such as embryogenesis, wound healing, morphogenesis, reproduction, tissue resorption and remodeling, and in pathological processes, such as inflammation, arthritis, cancer, cardiovascular and pulmonary diseases; hence, they are considered therapeutic targets $(17,18)$. Certain MMPs act as tumor suppressors, whereas others act as tumor promoters. MMP-9 is expressed mostly by stromal cells in a tumor environment, although cancer cells do express MMP-9 at low levels $(19,20)$. MMP-9 efficiently degrades native type IV and V collagens, fibronectin, ectactin and elastin. The regulation of MMP-9 activation is more complex than that of other MMPs, as most cells in general do not express the constitutively active form of MMP-9. Rather, its activity is 
induced by different stimuli depending on cell type, thereby contributing to specific pathological events $(21,22)$. Previous reports have demonstrated that transgenic mice lacking MMP-9 exhibit reduced keratinocyte hyperproliferation and a decreased incidence of invasive tumors (23). The imbalance between MMP activity and the inhibitory action of tissue inhibitors of metalloproteinase is implied in the regulation of multiple types of diseases. MMP-9 plays a crucial role in the modulation of cytokines and proteases, and in the degradation of the serine protease inhibitor $\alpha 1$-anti-trypsin, which leads to lung destruction. The early stage of a clinical trial has shown promising results using an MMP-9 inhibitor in multiple sclerosis. These observations suggest the hypothesis that MMP-9 is a potential drug target for both chronic obstructive pulmonary diseases and multiple sclerosis. Thus, the further development of highly potent and specific MMP-9 inhibitor is warranted $(24,25)$. In the present study, we report for the first time that quercetin and sulforaphane, when used in combination as opposed to alone, are more effective in suppressing cell migration and tumor growth through the down-regulation of MMP-9 expression, in in vitro as well as in vivo melanoma models.

\section{Materials and methods}

Statement of ethics. Animals were maintained in the experimental animal facilities of the National Center for Cell Science (NCCS), India, in accordance with the Institutional Animal Care and Use Committee (IACUC) guidelines (approval no. NCCS/IACUC/2007/B-107).

Cell culture and reagents. Mouse melanoma (B16F10) cells were obtained from the American Type Culture Collection (Manassas, VA, USA) and maintained in Dulbecco's modified Eagle's medium supplemented with 10\% FBS (Gibco), $100 \mathrm{U} / \mathrm{ml}$ penicillin, $100 \mu \mathrm{g} / \mathrm{ml}$ streptomycin and $2 \mathrm{mM}$ glutamine in a humidified atmosphere with $5 \% \mathrm{CO}_{2}$ at $37^{\circ} \mathrm{C}$. Quercetin (purity $>98 \%$ ) was purchased from HIMEDIA (India). D,L-sulforaphane (purity $>99 \%$ ) was a generous gift from Professor S.V. Singh of the University of Pittsburgh School of Medicine, PA, USA. Trypan blue dye was from Cambrex (Walkersville, MD, USA). Gelatin was from ICN (Aurora, OH, USA). Goat polyclonal anti-mouse MMP-9, anti-actin antibodies, horseradish peroxidase-conjugated IgG and Ultra-Cruz mounting media containing 4',6-diamidino2-phenylindole (DAPI) were purchased from Santa Cruz Biotechnology (Santa Cruz, CA, USA). The Cy2-conjugated anti-goat IgG was obtained from Calbiochem (La Jolla, CA, USA).

Cell viability assay. The effect of quercetin and sulforaphane on cell proliferation either alone or in combination was studied using the trypan blue dye exclusion assay as described previously (26). Briefly, B16F10 cells (1x104) were seeded in 24-well plates and treated with quercetin $(50 \mu \mathrm{M})$ or sulforaphane $(20 \mu \mathrm{M})$ or combinations of two doses of quercetin and sulforaphane (25 and $10 \mu \mathrm{M}$ or 50 and $20 \mu \mathrm{M}$, respectively) and then incubated for $16 \mathrm{~h}$. The number of viable cells were counted, analyzed and represented as the percentage of cell viability vs. treatment. Each of the experiments was performed in triplicate, and data were analyzed by one-way ANOVA and represented in the form of a bar graph.

Wound migration assay. The wound migration assay was performed as described previously (27). Briefly, B16F10 cells were seeded and grown to confluency. Wounds with a constant diameter were made using sterile tips, and the cells were treated with quercetin and sulforaphane either individually or in combination under similar conditions as described above. The wound images were captured at 0 and $16 \mathrm{~h}$ using a phase contrast microscope (Nikon). The wound assay data were analyzed, quantified and represented in the form of a bar graph using Image Pro-plus 6.0 software (Nikon) and one-way ANOVA.

In vivo tumorigenicity and immunofluorescence experiments. The tumorigenicity and immunohistochemistry experiments were performed as described previously $(28,29)$. B16F10 cells $\left(1.5 \times 10^{6}\right)$ were injected subcutaneously into the right flanks of male C57 BL6 mice (4-6 weeks of age). Animals were randomly separated into 5 groups (6 mice/group). Quercetin (15 mg/kg body weight) or sulforaphane $(3.5 \mathrm{mg} / \mathrm{kg}$ body weight) was injected thrice a week into the peripheral sites of tumors for 3 weeks. In seperate experiments, a combination of quercetin $(7.5 \mathrm{mg} / \mathrm{kg}$ body weight) and sulforaphane (1.75 $\mathrm{mg} / \mathrm{kg}$ body weight) was injected into the peripheral sites of tumors. In another experiment, a combination of quercetin $(15 \mathrm{mg} / \mathrm{kg}$ body weight) and sulforaphane $(3.5 \mathrm{mg} /$ $\mathrm{kg}$ body weight) was injected. Animals were maintained in the experimental animal facilities of the NCCS, India, in accordance with IACUC guidelines. At the termination of the experiments, all animals were sacrificed, tumors were photographed, excised and weighed, and the volumes [0.5 (length $\mathrm{x}$ breadth $\left.\left.{ }^{2}\right)\right]$ were calculated. Paraffin-embedded tumor sections were used for immunofluorescence analysis. Briefly, sections were deparafinized, rehydrated, used for heat-induced antigen retrieval and quenched. The sections were blocked with $2 \%$ bovine serum albumin and incubated with an anti-MMP-9 antibody (1:20). The sections were washed and incubated with Cy2-conjugated anti-goat IgG and counterstained with mounting media containing DAPI and analyzed using a confocal microscope (Zeiss).

Western blot analysis and zymography experiment. Western blotting was performed as previously described (30). Tumor samples were lysed in RIPA lysis buffer $(50 \mathrm{mM}$ Tris- $\mathrm{HCl}$ $\mathrm{pH} 7.4,150 \mathrm{mM} \mathrm{NaCl}, 1 \%$ Nonidet P-40, $1 \%$ Triton X-100, $1 \%$ sodium deoxycholate, $0.2 \% \mathrm{SDS}, 5 \mathrm{mM}$ iodoacetamide containing $1 \mathrm{mM}$ DTT and $2 \mathrm{mM}$ PMSF), and the protein concentration in the lysates was measured using the Bio-Rad protein assay. The samples containing an equal amount of total proteins $(40 \mu \mathrm{g})$ were resolved by $7.5 \%$ sodium dodecyl sulfate-polyacrylamide gel electrophoresis (SDS-PAGE) and electrotransferred onto nitrocellulose membranes. The membranes were incubated with goat anti-MMP-9 antibody $(1: 2,000)$, further incubated with horseradish peroxidaseconjugated anti-goat IgG $(1: 4,000)$ and detected by Western blotting using a luminol reagent (Santa Cruz Biotechnology).

The gelatinolytic activity was measured as described previously (31). To assess the effect of quercetin and 
A

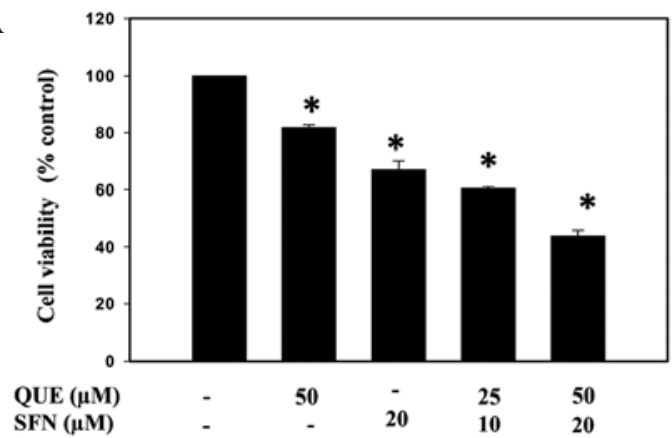

C

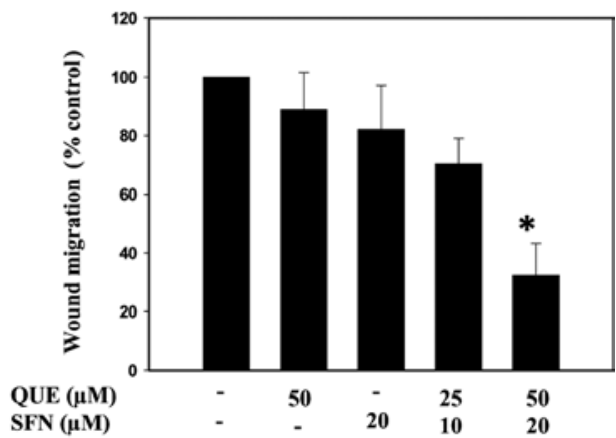

B
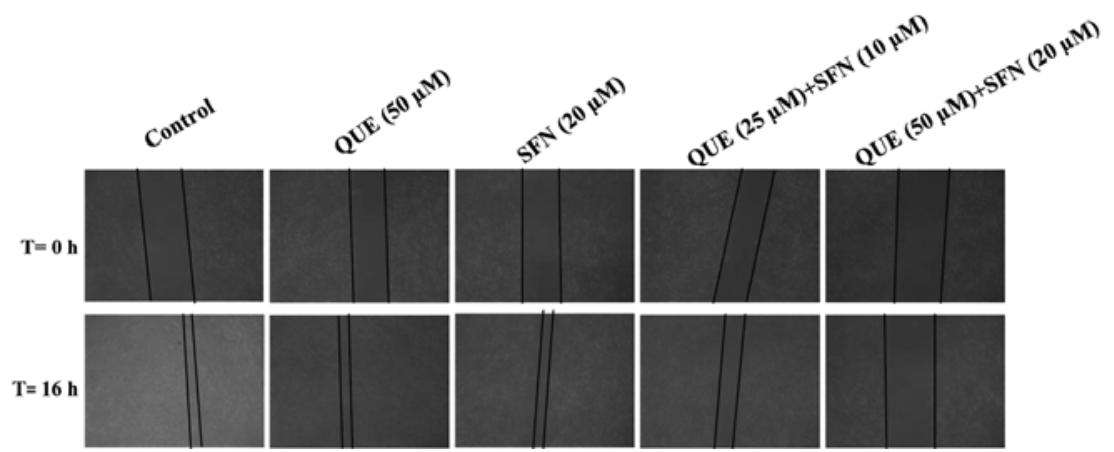

Figure 1. Inhibitory effect of quercetin (QUE) and sulforaphane (SFN) on B16F10 melanoma cell proliferation and cell motility. (A) B16F10 cells (1x104) were either treated with QUE $(50 \mu \mathrm{M})$ or SFN $(20 \mu \mathrm{M})$, or a combination of the two for $16 \mathrm{~h}$. Cell viability was measured by trypan blue dye exclusion assays. The data were analyzed and represented as the percentage of cell viability vs. treatment in the form of bar graphs. The error bars indicate the standard error of the mean in triplicate. The values were analyzed by one way ANOVA ( $\mathrm{p}<0.05)$. (B) The wound migration assay was carried out as described in Materials and methods. B16F10 cells were either treated with QUE $(50 \mu \mathrm{M})$ or SFN $(20 \mu \mathrm{M})$, or a combination of the two for $16 \mathrm{~h}$. Images of the wounds were captured at 0 and $16 \mathrm{~h}$. (C) Wound migration data were quantified and represented as the percentage of wound migration vs. treatment in the form of a bar graph. The error bars indicate the standard error of the mean. Experiments were performed in triplicate and analyzed by one-way ANOVA ("p $<0.05)$.

sulforaphane on MMP-9 expression, an equal amount of total proteins from tumor lysates was mixed with sample buffer in the absence of a reducing agent, incubated for $30 \mathrm{~min}$ and separated by $7.5 \%$ zymography-SDS-PAGE containing gelatin $(0.5 \mathrm{mg} / \mathrm{ml})$. The gel was washed with $0.25 \%$ Triton $\mathrm{X}-100$ and incubated in incubation buffer $[50 \mathrm{mM}$ Tris- $\mathrm{HCl}$ (pH 7.5) containing $100 \mathrm{mM} \mathrm{CaCl} 2,1 \mu \mathrm{M} \mathrm{ZnCl}_{2}, 1 \%$ Triton $\mathrm{X}-100,0.02 \%(\mathrm{w} / \mathrm{v}) \mathrm{NaN}_{3}$ ]. Negative staining indicated the zones of gelatinolytic activity.

\section{Results}

Effect of quercetin or sulforaphane alone or in combination on B16F10 cell proliferation. Previous reports have revealed that quercetin or sulforaphane inhibit cancer cell proliferation in an independent manner $(9,32)$. We therefore examined whether a combination of quercetin and sulforaphane confers a significant effect on the proliferation of B16F10 cells. Accordingly, B16F10 cells were treated with quercetin $(50 \mu \mathrm{M})$ or sulforaphane $(20 \mu \mathrm{M})$ either alone or in a combination of two different doses as described in the Materials and methods, and cell proliferation assays were performed using the trypan blue dye exclusion test. The results indicated that quercetin and sulforaphane in combination had a stronger inhibitory effect on the growth of B16F10 cells than either compound alone (Fig. 1A). The data were analyzed by one-way ANOVA and represented in the form of a bar graph $(\mathrm{p}<0.05)$.
Effect of quercetin or sulforaphane alone or in combination on B16F10 melanoma cell motility. To ascertain whether quercetin and sulforaphane exhibit a combinatorial effect on B16F10 cell motility, a wound migration assay was performed. Cells were grown in monolayer to attain cobblestone morphology and were treated with quercetin $(50 \mu \mathrm{M})$ or sulforaphane $(20 \mu \mathrm{M})$, or with a combination of two different doses for $16 \mathrm{~h}$ as described above. The data indicated that a combination of quercetin and sulforaphane inhibited melanoma cell migration more significantly compared to treatment with each agent individually (Fig. 1B). The data were analyzed using Image Pro plus 6.0 software (Nikon) and one-way ANOVA. Fig. 1C shows a graphical representation of the percentage of wound migration with respect to the control $(\mathrm{p}<0.05)$.

Quercetin and sulforaphane in combination suppress melanoma growth in C57 BL6 mice. Our in vitro results prompted us to investigate the combined effect of quercetin and sulforaphane on melanoma growth in a mouse model. Accordingly, B16F10 cells were injected into the right flanks of C57 BL6 mice. After 1 week, quercetin or sulforaphane, either alone or in combination, were injected at the peripheral site of the tumors thrice a week for 3 weeks. The data revealed that a combination of quercetin and sulforaphane is more effective in suppressing melanoma growth than each agent used alone (Fig. 2A). Mice were sacrificed by cervical dislocation. Tumors were excised and weighed, and the volume was calculated as described in Materials and 
A

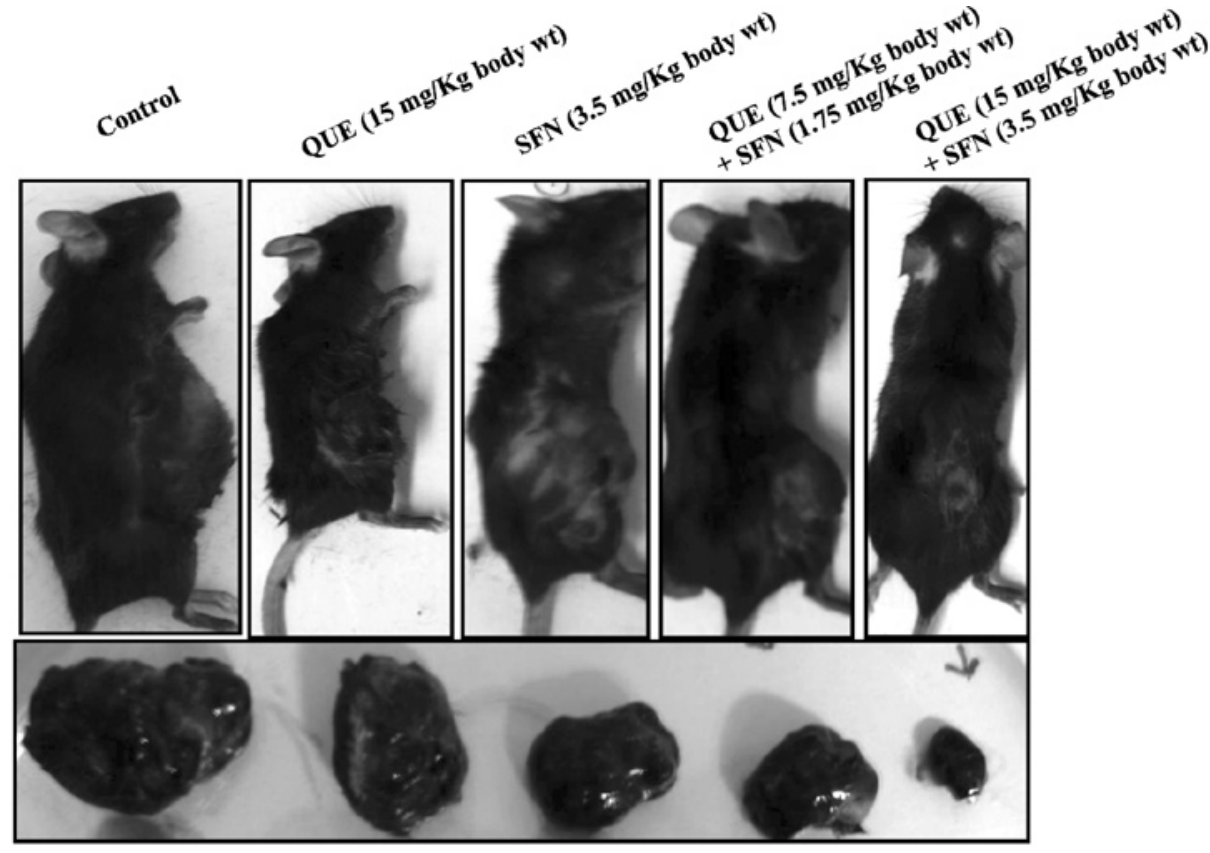

B

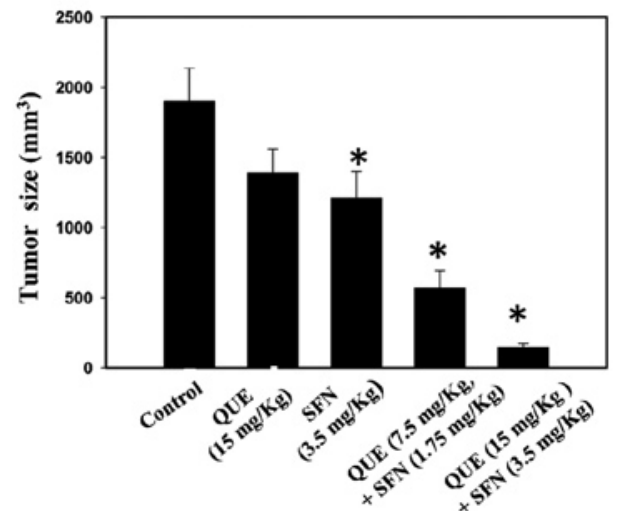

C

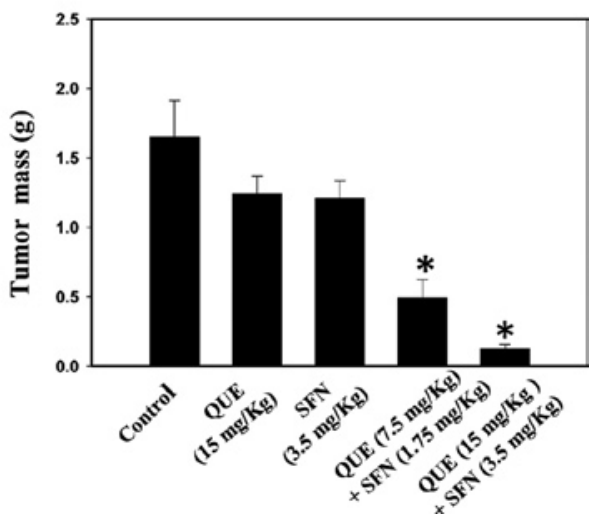

Figure 2. Quercetin (QUE) and sulforaphane (SFN) in combination suppress melanoma growth in a mouse isograft model. B16F10 cells $\left(1.5 \times 10^{6}\right)$ were injected subcutaneously into C57 BL6 mice. Various doses of QUE or SFN, either alone or in combination, were injected at the peripheral site of the tumors as described in the Materials and methods. After 3 weeks, the mouse tumors were photographed, excised (A), and tumor volume and weight were measured and represented in the form of bar graphs (B and C). The data were analyzed by one-way ANOVA. The error bars indicate the standard error of the mean ( $\mathrm{n}=6$ ) $\left({ }^{*} \mathrm{p}<0.05\right)$.

methods. The tumor volumes and weights were analyzed by one-way ANOVA $(\mathrm{p}<0.05)$ and represented in the form of bar graphs (Fig. 2B and C).

Quercetin and sulforaphane reduce tumor growth through the down-regulation of MMP-9 expression. To elucidate the molecular mechanism of tumor growth suppression in response to quercetin and sulforaphane, formalin-fixed tumor sections were analyzed by immunofluorescence using an anti-MMP-9 antibody. The data revealed that the expression of MMP-9 in tumor sections from the mice treated with a combination of quercetin and sulforaphane was significantly decreased as compared to tumors from the control mice or mice treated with quercetin or sulforaphane alone (Fig. 3A, panel a). Panels $b$ and $c$ show nuclear staining by DAPI and merged images, respectively.

The expression of MMP-9 in tumor lysates was further confirmed by Western blot analysis and gelatin zymography. Tumor tissues were lysed, and an equal amount of total proteins in the lysates were analyzed by gelatin zymography. The zymography data showed that the expression of proMMP-9 in tumors from the mice treated with quercetin and sulforaphane in combination was dramatically reduced as compared to tumors from the control mice or mice treated with either compound alone (Fig. 3B). This was further confirmed by Western blot analysis using an anti-MMP-9 antibody (Fig. 3C). Taken together, these data strongly suggest that quercetin and sulforaphane in combination inhibit proMMP-9 expression, which in turn suppresses melanoma progression in a mouse model.

\section{Discussion}

Historically, plant-derived compounds have been used as traditional medicines in Asian countries as well as worldwide (33). Many of these plant products have shown great potential to act as anti-carcinogenic, anti-inflammatory and anti-diabetic agents (33). However, higher concentrations of 
A

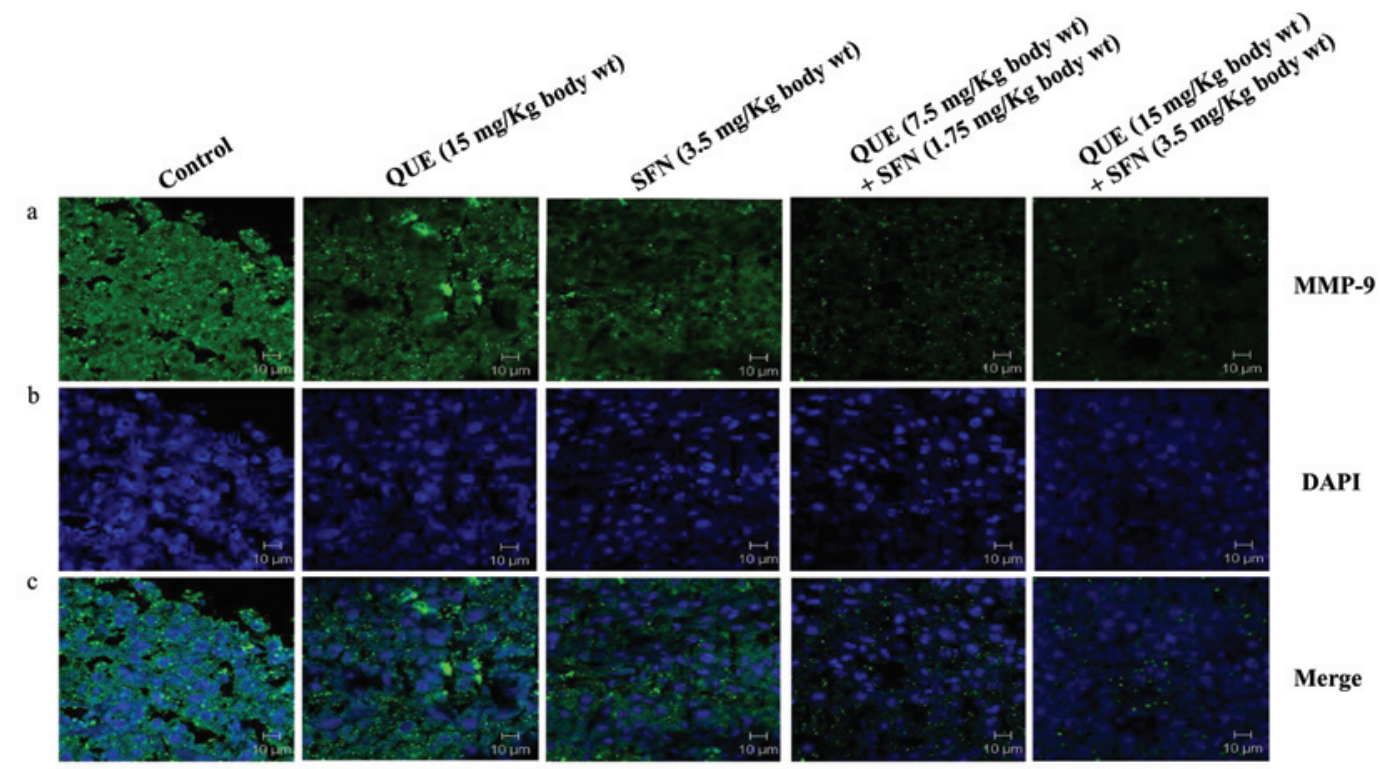

B

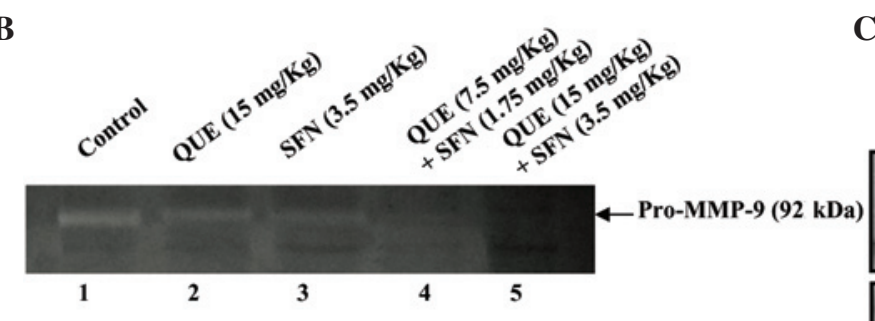

C

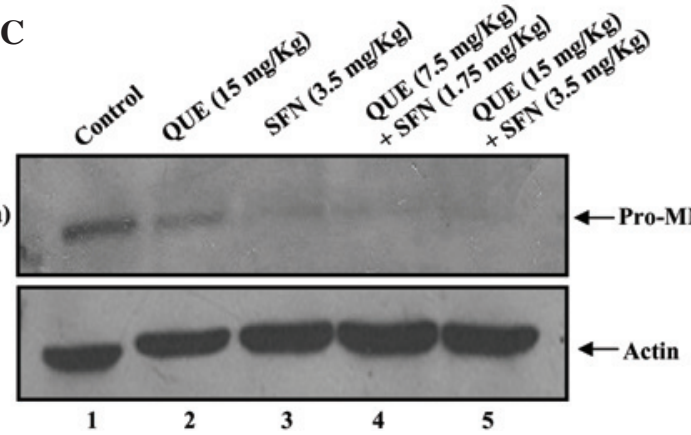

Figure 3. Quercetin (QUE) and sulforaphane (SFN) in combination inhibit the expression of MMP-9 in mouse tumors. (A) The localization of MMP-9 in mouse tumors was visualized by immunofluorescence using an anti-MMP-9 antibody and staining with Cy2-conjugated IgG (green). Nuclei were counterstained with DAPI (blue). Images were captured using a confocal microscope (Zeiss). (B and C) Tumor lysates containing an equal amount of total proteins were analyzed by zymography (B) and Western blot analysis (C). Actin was used as a loading control. Lane 1, control (untreated tumor lysates); lane 2, QUE ( $15 \mathrm{mg} / \mathrm{kg}$ body weight); lane 3, SFN (3.5 mg/kg body weight); lane 4, QUE (7.5 mg/kg body weight) and SFN (1.75 mg/kg body weight); lane 5 , QUE (15 mg/ $\mathrm{kg}$ body weight) and SFN (3.5 $\mathrm{mg} / \mathrm{kg}$ body weight).

these compounds are required to show significant inhibitory effects. Therefore, combination studies using two or more such pharmacologically active compounds may increase the efficacy of the drug and overcome the hurdle of drug resistance.

The present study demonstrated the anti-carcinogenic/ anti-tumor activity of a plant-derived flavonoid, quercetin, and an isothiocyanate, sulforaphane, on melanoma progression when used in combination. Previous reports have revealed that quercetin and sulforaphane act as anti-cancer agents in various cancer models when used individually (5-9). Lin et al showed that quercetin inhibits tumor cell motility and invasion through PKCס/ERK/AP-1-dependent MMP-9 activation in breast cancinoma cells (34). Our in vitro data suggest that a combination of quercetin and sulforaphane inhibits melanoma cell proliferation more effectively than each used independently. The combination treatment also significantly inhibits melanoma cell motility. Our results revealed that the use of quercetin and sulforaphane at the ratio 2.5:1 is quite effective against the proliferation and migration of B16F10 cells.

Our in vitro results prompted us to examine the effects of quercetin and sulforaphane in an in vivo melanoma model. The B16F10 cells were injected subcutaneously into the right flanks of C57 BL6 mice. Tumors were generated, and quercetin and sulforaphane, either independently or in combination, were injected into the peripheral site of the tumors. Notably, quercetin and sulforaphane in combination drastically suppressed melanoma growth as compared to the agents used independently in a mouse isograft model. However, the molecular mechanism by which quercetin and sulforaphane inhibit melanoma growth has not yet been fully understood. Zhang et al reported that quercetin inhibits the invasion of murine melanoma B16BL6 cells by decreasing pro-MMP-9 via the PKC pathway (35). Therefore, we examined the status of pro-MMP-9 expression in the tumors treated with quercetin and sulforaphane in combination. As shown using immunofluorescence, zymography and Western blotting, the level of expression of MMP-9 was reduced significantly in tumors treated with lower and higher doses of the two compounds as compared to the control or their individual use. These data demonstrated that combination therapy is more effective than the use of a single compound for the treatment of melanoma growth.

In summary, for the first time we report that quercetin and sulforaphane in combination are much more effective in regulating melanoma progression through the down-regulation of 
MMP-9 expression than each compound used alone. Thus, inhibiting MMP-9 expression by quercetin and sulforaphane in combination may be a novel therapeutic strategy for the prevention of melanoma progression.

\section{Acknowledgements}

We thank Professor S.V. Singh of the University of Pittsburgh School of Medicine, PA, USA, for providing the sulforaphane. The study was partially supported by the Council of Scientific and Industrial Research, Government of India, India (to R. Mishra and P. Sharma).

\section{References}

1. Gray-Schopfer V, Wellbrock C and Marais R: Melanoma biology and new targeted therapy. Nature 445: 851-857, 2007.

2. Verhoeven DT, Goldbohm RA, van Poppel G, Verhagen H and van den Brandt PA: Epidemiological studies on brassica vegetables and cancer risk. Cancer Epidemiol Biomarkers Prev 5: 733-748, 1996.

3. Zhang SM, Hunter DJ, Rosner BA, Giovannucci EL, Colditz GA, Speizer FE and Willett WC: Intakes of fruits, vegetables, and related nutrients and the risk of non-Hodgkin's lymphoma among women. Cancer Epidemiol Biomarkers Prev 9: 477-485, 2000.

4. Bedikian AY, Millward M, Pehamberger H, Conry R, Gore M, Trefzer U, Pavlick AC, DeConti R, Hersh EM, Hersey P, Kirkwood JM and Haluska FG: Bcl-2 antisense (oblimersen sodium) plus dacarbazine in patients with advanced melanoma: the Oblimersen Melanoma Study Group. J Clin Oncol 24 4738-4745, 2006.

5. Musonda CA and Chipman JK: Quercetin inhibits hydrogen peroxide $\left(\mathrm{H}_{2} \mathrm{O}_{2}\right)$-induced NF-kappaB DNA binding activity and DNA damage in HepG2 cells. Carcinogenesis 19: 1583-1589, 1998.

6. Avila MA, Velasco JA, Cansado J and Notario V: Quercetin mediates the down-regulation of mutant p53 in the human breast cancer cell line MDA-MB468. Cancer Res 54: 2424-2428, 1994.

7. Vijayababu MR, Arunkumar A, Kanagaraj P, Venkataraman P, Krishnamoorthy G and Arunakaran J: Quercetin downregulates matrix metalloproteinases 2 and 9 proteins expression in prostate cancer cells (PC-3). Mol Cell Biochem 287: 109-116, 2006.

8. Choi S and Singh SV: Bax and Bak are required for apoptosis induction by sulforaphane, a cruciferous vegetable-derived cancer chemopreventive agent. Cancer Res 65: 2035-2043, 2005.

9. Zhang Y, Tang L and Gonzalez V: Selected isothiocyanates rapidly induce growth inhibition of cancer cells. Mol Cancer Ther 2: 1045-1052, 2003.

10. Zhang W and Zhang F: Effects of quercetin on proliferation, apoptosis, adhesion and migration, and invasion of HeLa cells. Eur J Gynaecol Oncol 30: 60-64, 2009.

11. Braganhol E, Zamin LL, Canedo AD, Horn F, Tamajusuku AS, Wink MR, Salbego C and Battastini AM: Antiproliferative effect of quercetin in the human U138MG glioma cell line. Anticancer Drugs 17: 663-671, 2006.

12. Dashwood RH and Ho E: Dietary histone deacetylase inhibitors: from cells to mice to man. Semin Cancer Biol 17: 363-369, 2007.

13. Juge N, Mithen RF and Traka M: Molecular basis for chemoprevention by sulforaphane: a comprehensive review. Cell Mol Life Sci 64: 1105-1127, 2007.

14. Singh AV, Xiao D, Lew KL, Dhir R and Singh SV: Sulforaphane induces caspase-mediated apoptosis in cultured PC-3 human prostate cancer cells and retards growth of PC-3 xenografts in vivo. Carcinogenesis 25: 83-90, 2004.

15. Myzak MC, Tong P, Dashwood WM, Dashwood RH and Ho E: Sulforaphane retards the growth of human PC-3 xenografts and inhibits HDAC activity in human subjects. Exp Biol Med 232: 227-234, 2007.

16. Thejass $P$ and Kuttan G: Antimetastatic activity of sulforaphane. Life Sci 78: 3043-3050, 2006.

17. Parks WC, Wilson CL and Lopez-Boado YS: Matrix metalloproteinases as modulators of inflammation and innate immunity. Nat Rev Immunol 4: 617-629, 2004.
18. Shapiro SD: Matrix metalloproteinase degradation of extracellular matrix: biological consequences. Curr Opin Cell Biol 10: 602-608, 1998.

19. Pyke C, Ralfkiaer E, Tryggvason K and Dano K: Messenger RNA for two type IV collagenases is located in stromal cells in human colon cancer. Am J Pathol 142: 359-365, 1993.

20. Zeng ZS and Guillem JG: Colocalisation of matrix metalloproteinase-9-mRNA and protein in human colorectal cancer stromal cells. Br J Cancer 74: 1161-1167, 1996.

21. Houde $\mathbf{M}$, de Bruyne $G$, Bracke $\mathbf{M}$, Ingelman-Sundberg $\mathbf{M}$, Skoglund G, Masure S, van Damme J and Opdenakker G: Differential regulation of gelatinase $\mathrm{B}$ and tissue-type plasminogen activator expression in human Bowes melanoma cells. Int J Cancer 53: 395-400, 1993.

22. Rangaswami H, Bulbule A and Kundu GC: Nuclear factor inducing kinase plays crucial role in osteopontin induced MAPK/IKK dependent nuclear factor $\mathrm{\kappa B}$-mediated promatrix metalloproteinase-9 activation. J Biol Chem 279: 38921-38935, 2004.

23. Coussens LM, Tinkle CL, Hanahan D and Werb Z: MMP-9 supplied by bone marrow-derived cells contributes to skin carcinogenesis. Cell 103: 481-490, 2000.

24. Muroski ME, Roycik MD, Newcomer RG, van den Steen PE, Opdenakker G, Monroe HR, Sahab ZJ and Sang QX: Matrix metalloproteinase-9/gelatinase B is a putative therapeutic target of chronic obstructive pulmonary disease and multiple sclerosis. Curr Pharm Biotechnol 9: 34-46, 2008.

25. Ram M, Sherer Y and Shoenfeld Y: Matrix metalloproteinase- 9 and autoimmune diseases. J Clin Immunol 26: 299-307, 2006.

26. Xiao D, Choi S, Johnson DE, Vogel VG, Johnson CS, Trump DL, Lee YJ and Singh SV: Diallyl trisulfide-induced apoptosis in human prostate cancer cells involves c-Jun N-terminal kinase and extracellular-signal regulated kinase-mediated phosphorylation of Bcl-2. Oncogene 23: 5594-5606, 2004.

27. Behera R, Kumar V, Lohite K, Karnik S and Kundu GC: Activation of JAK2/STAT3 signaling by osteopontin promotes tumor growth in human breast cancer cells. Carcinogenesis 31: 192-200, 2010.

28. Philip S, Bulbule A and Kundu GC: Osteopontin stimulates tumor growth and activation of promatrix metalloproteinase-2 through nuclear factor-kappa B-mediated induction of membrane type 1 matrix metalloproteinase in murine melanoma cells. J Biol Chem 276: 44926-44935, 2001.

29. Chakraborty G, Jain S and Kundu GC: Osteopontin promotes vascular endothelial growth factor-dependent breast tumor growth and angiogenesis via autocrine and paracrine mechanisms. Cancer Res 68: 152-161, 2008.

30. Jain S, Chakraborty G and Kundu GC: The crucial role of cyclooxygenase- 2 in osteopontin-induced protein kinase $\mathrm{C}$ alpha/c-Src/IkappaB kinase alpha/beta-dependent prostate tumor progression and angiogenesis. Cancer Res 66: 6638-6648, 2006.

31. Philip S and Kundu GC: Osteopontin induces nuclear factor kappa B-mediated promatrix metalloproteinase-2 activation through I kappa B alpha /IKK signaling pathways, and curcumin (diferulolylmethane) down-regulates these pathways. J Biol Chem 278: 14487-14497, 2003.

32. Jeong JH, An JY, Kwon YT, Rhee JG and Lee YJ: Effects of low dose quercetin: cancer cell-specific inhibition of cell cycle progression. J Cell Biochem 106: 73-82, 2009.

33. Aggarwal BB and Shishodia S: Molecular targets of dietary agents for prevention and therapy of cancer. Biochem Pharmacol 71: 1397-1421, 2006.

34. Lin CW, Hou WC, Shen SC, Juan SH, Ko CH, Wang LM and Chen YC: Quercetin inhibition of tumor invasion via suppressing PKCD/ERK/AP-1-dependent matrix metalloproteinase-9 activation in breast carcinoma cells. Carcinogenesis 29: 1807-1815, 2008.

35. Zhang X-M, Huang S-P and Xu Q: Quercetin inhibits the invasion of murine melanoma B16BL6 cells by decreasing pro-MMP-9 via the PKC pathway. Cancer Chemother Pharmacol 53: 82-88, 2004. 